Article

\title{
Characterization of Polyphenolic Compounds Extracted from Different Varieties of Almond Hulls (Prunus dulcis L.)
}

\author{
Maher Kahlaoui ${ }^{1,2, *}$, Stefania Borotto Dalla Vecchia ${ }^{1}$, Francesco Giovine ${ }^{1}$, \\ Hayet Ben Haj Kbaier ${ }^{2}$, Nabiha Bouzouita ${ }^{2}$, Letricia Barbosa Pereira ${ }^{1,3}$ [D \\ and Giuseppe Zeppa ${ }^{1, *(1)}$ \\ 1 Department of Agriculture, Forest and Food Sciences (DISAFA), University of Turin, Largo Paolo Braccini, 2, \\ 10095 Torino, Italy; stefania.borottodallavecchia@unito.it (S.B.D.V.); francescogiovine7@gmail.com (F.G.); \\ letricia.barbosapereira@unito.it (L.B.P.) \\ 2 Higher School of Food Industries of Tunis (ESIAT), University of Carthage, 1003, 58 Alain Savary, Tunisia; \\ h.kbaier@gmail.com (H.B.H.K.); bouzouita.nabiha@gmail.com (N.B.) \\ 3 Department of Analytical Chemistry, Nutrition and Food Science, Faculty of Pharmacy, \\ University of Santiago de Compostela, 15782 Santiago de Compostela, Spain \\ * Correspondence: maher.kahlaoui@unito.it (M.K.); giuseppe.zeppa@unito.it (G.Z.)
}

Received: 1 December 2019; Accepted: 13 December 2019; Published: 16 December 2019

check for updates

\begin{abstract}
Ultrasound-assisted extraction (UAE) was applied as a pretreatment technique to improve the recovery of polyphenols from the almond hulls of four Tunisian and three Italian almond varieties, followed by the characterization with HPLC-DAD. The operating parameters (solid/liquid ratio, extraction time, and ethanol concentrations) were optimized using a Response Surface Methodology. A polynomial equation was calculated to describe the relationship between the operating parameters and dependent variables as total polyphenolic content (TPC) and antioxidant activity (RSA). A desirability function approach was used to determine the optimum conditions for operating parameters: a solid:solvent ratio of $2 \mathrm{~g} / 100 \mathrm{~mL}$, an extraction time of $13 \mathrm{~min}$, and an ethanol concentration of $51.2 \%$. Among the almond varieties, Pizzuta and Fakhfekh showed the highest polyphenol content and antioxidant activity. HPLC-DAD analysis of almond hull extracts confirmed that chlorogenic acid, catechin, and protocatechuic acid were the most important polyphenols in almond hull. The results highlighted that UAE could be an effective technique for the recovery of phenolic compounds from almond hull, thereby making this byproduct a promising source of compounds with potential applications in food and healthcare sectors.
\end{abstract}

Keywords: almond hull; Prunus dulcis L.; ultrasound-assisted extraction; response surface methodology; radical scavenging activity; polyphenols

\section{Introduction}

Almond (Prunus dulcis (Mill.), Prunus amygdalus (Batch), or Amygdalus communis (L.)), is a deciduous tree native to Iran, its surrounding countries, and Central Asia, but is widely cultivated elsewhere under different climates and growing conditions. The almond tree belongs to the Rosaceae family, genus Prunus with peach, plum, apricot, cherry, and nectarine, a group of fruits collectively known as "stone fruits" i.e., fruits with a stony endocarp. The United States of America, and in particular, California, is the main producer of almonds globally, with a production of about 1.02 million tons in 2017, compared with the worldwide production of about 2.2 million tons in the same year [1]. The edible part of almonds, the kernel, is a seed with two large cotyledons. In the last several years, market demand for almonds as edible nuts and as an ingredient in manufactured food products 
has significantly increased due to the physico-chemical, nutritional, and sensorial features of this fruit. Indeed, almond kernel is consumed worldwide raw, cooked or dry-roasted, sliced or whole, and blanched (without the skin) or unblanched (with the skin). It is extensively used in bakery and confectionery products and in food preparation in general, but also in pharmaceutical and cosmetic applications. The growing interest in almonds is based on their richness in lipids (about $50 \%$ of kernel weight), proteins (16-22\% of the kernel weight), dietary fiber (10.8-13.5\% of the kernel weight), and minerals [2], as well as their high concentrations of phenolic compounds including benzoic and cinnamic derivates, flavonols, anthocyanidins, and procyanidins [3]. Recent studies have evidenced their beneficial effects due to the capacity of their bioactive nutrients and nonnutrients to lower the plasma level of low-density lipoprotein cholesterol and the incidence and severity of cardiovascular disorder [2].

Unfortunately, almond seed production generates large amounts of byproducts, the heaviest of which is the hull, accounting for $35-62 \%$ of the total fresh weight of almond [2].

Generally, almond hulls are considered to be of low economic value, and are used as livestock feed and fuel [2]. However, if fresh, they can also have culinary applications, in addition to many medicinal properties when integrated into a diet, as they are thought to reduce cholesterol levels [4].

Almond hulls are rich source of triterpenoids (betulinic, urosolic, and oleanolic acids) flavonol glycosides, phenolic acids, catechin, protocatechuic acid, vanillic acid, and other polyphenolioc compounds; therefore, this byproduct may be an interesting source of natural antioxidants and other bioactive compounds [4-6]. Moreover, the extraction of these products from almond residues could contribute to a reduction in the environmental impact and provide added value to the overall almond production.

There are many techniques for recovering phenolic compounds from plant and vegetable materials, but the classic extraction techniques for bioactive compounds (e.g., maceration or simple agitation) generally require long durations, along with high solvent quantities and high temperatures [7], thus risking the thermal degradation of most bioactive compounds $[8,9]$. Consequently, to reduce the solvent consumption and extraction duration while increasing the extraction yield and purity of extracts, novel, efficient, and advanced extraction methods have been developed, including super critical fluid extraction (SCFE), ultrasound-assisted extraction (UAE), and microwave-assisted extraction (MAE). In particular ultrasound-assisted extraction relies on acoustic cavitation, which causes disruptions of the cell walls in plant materials, resulting in an extensive release of internal cell compounds and a relatively homogeneous system $[10,11]$. Since this technique is inexpensive, simple, and effective at the industrial scale [12], several studies have investigated the application of UAE in order to extract bioactive compounds from plants materials also using various novel extractants [13-17].

To the best of our knowledge, no study has reported the application of UAE for the extraction of polyphenols from almond hull. Therefore, the objective of the current study was to characterize, for the first time, the recovery of polyphenolic compounds from the almond hulls of Italian and Tunisian varieties by applying UAE. The effects of different processing parameters of UAE (solid:solvent ratio, extraction time and ethanol concentration) on polyphenol recovery from almond hulls were optimized using a Response Surface Methodology.

\section{Material and Methods}

\subsection{Chemicals}

Folin-Ciocalteu's phenol reagent, 2,2-diphenyl-1-picrylhydrazyl (95\%) (DPPH), 6-hydroxy-2,5,7,8-tetramethylchroman-2-carboxylic acid (97\%) (Trolox), sodium carbonate $(\geq 99.5 \%)$, vanillin $(99 \%)$, aluminium chloride $(99 \%)$, sodium nitrite $(\geq 99 \%),(+)$-catechin hydrate ( $>98 \%$ ), methanol ( $\geq 99.9 \%)$, formic acid (98-100\%), and hydrochloric acid (fuming $37 \%$ ) were obtained from Sigma-Aldrich (Milano, Italy). 
All standards for phenolic and organic acids, including chlorogenic, protocatechuic, quercetin-3-glucoside, p-coumaric acids, and caffeic acid were purchased from Sigma-Aldrich (Milano, Italy). Ethanol ( $\geq 70 \%$ and $\geq 99.9 \%)$, gallic acid, epicatechin, and sodium hydroxide $(1 \mathrm{M})$ were obtained from Fluka (Milano, Italy). All chemicals were of reagent or HPLC grade, and ultra-pure water was produced using a Milli-Q System (Millipore, Milano, Italy).

\subsection{Samples}

The optimization of UAE was carried out with almond hulls of the Zahaf variety, harvested from the Midwest of Tunisia. The hulls were ground with a ZM200 grinder (Retsch Gmbh, Haan, Germany) to a particle size ranging between 200 and $250 \mu \mathrm{m}$. The powder was stored in vacuum-sealed polyethylene bags at $4{ }^{\circ} \mathrm{C}$ until analysis.

The optimized UAE process was applied to the hulls of three Italian almond varieties (Fascionello, Pizzuta, and Romana), provided by the "Consorzio della Mandorla d'Avola" (Avola, Italy), and four Tunisian almond varieties (Achaak, Fakhfekh, Laurane, and Zahaf), provided by the Tunisian office of almond and olive oils (Sfax, Tunisia). All samples were ground using a ZM200 grinder (Retsch Gmbh, Haan, Germany) to a particle size between 200 and $250 \mu \mathrm{m}$. The powder was stored in vacuum-sealed polyethylene bags at $4{ }^{\circ} \mathrm{C}$ until analysis. The dry mater content of the samples was determined at $105^{\circ} \mathrm{C}$ using a Gibertini Eurotherm electronic moisture balance (Gibertini Elettronica, Novate Milanese MI, Italy).

\subsection{Extraction Procedure}

\subsubsection{Ultrasound-Assisted Extraction (UAE)}

The powdered hulls of each almond variety were added to an ethanol/water solution to obtain a 100-mL solution. The solid:solvent ratio and ethanol concentrations were assigned according to the experimental design. Extractions were performed with an ultrasonic bath PEX1-S (REUS, France) at a frequency of $40 \mathrm{kHz}$ and $300 \mathrm{~W}$ of power. The extraction duration was also assigned according to the experimental design. The temperature of extraction was $25^{\circ} \mathrm{C}$, maintained by an external circulation of cold water obtained from a chiller. All the extracts were centrifuged at $5600 \times g$ for $5 \mathrm{~min}$ at $25^{\circ} \mathrm{C}$, and the supernatants were collected and filtered through a $0.45-\mu \mathrm{m}$ nylon membrane filter. Samples were stored at $-18^{\circ} \mathrm{C}$ in the dark before analysis. For almond hull characterization, the UAE extractions were done in triplicate.

\subsubsection{Conventional Solid-Solvent Extraction (CSE)}

Conventional extraction was carried out according to Azadeh [18]. Briefly, $10 \mathrm{~g}$ of almond hull powder was mixed with $100 \mathrm{~mL}$ of ethanol/water solution $(70 / 30, v / v)$, and the extraction was performed at $50{ }^{\circ} \mathrm{C}$ for $6 \mathrm{~h}$ with a VDRL 711 orbital shaker (Asal S.r.l., Milan, Italy) under constant rotatory agitation at $60 \mathrm{rpm}$.

All extracts were centrifuged at $5600 \times g$ for $5 \mathrm{~min}$ at $25^{\circ} \mathrm{C}$, and the supernatants were then collected and filtered through a $0.45-\mu \mathrm{m}$ nylon membrane filter. The samples were stored in amber vials at $-18{ }^{\circ} \mathrm{C}$. All extractions were done in triplicate.

\subsection{Experimental Design}

A Central Composite Design (CCD) was followed to allow the fitting of a second-order model, using the Design-Expert software 11.0 (Stat-Ease, Inc., Minneapolis, MN, USA). The CCD consisted of 20 experiments with six replicates at the central point.

All experiments were performed in a random order to minimize the effect of unexplained variability in the observed response due to systematic errors.

The range of each variable was selected according to the results from preliminary experiments, where the effects on the polyphenolic content of hull extracts were assessed for different solid:solvent 
ratios $(2,2.5,3.3,5$, and $10 \mathrm{~g} / 100 \mathrm{~mL})$, ethanol concentrations $(20 \%, 40 \%, 60 \%, 80 \%$, and $100 \% v / v)$, and extraction times $(1,5,10,15,20,25$, and $30 \mathrm{~min})$, using single-factor experiments. All extractions conditions were done in duplicate. For each extraction, the variables not being studied were kept constant at the central value.

Each independent variable was coded at five levels, i.e., $-1.6818,-1,0,+1$, and +1.6818 , according to the following equation:

$$
X_{i}=\frac{x_{i}-x_{0}}{\Delta x}
$$

where $X_{\mathrm{i}}$ is the coded value of an independent variable, $x_{\mathrm{i}}$ is the real value of an independent variable, $x_{0}$ is the mean of the real value of an independent variable, and $\Delta x$ is the step change in value.

Response Surface Methodology (RSM) with a Box-Behnken design was employed to determine the optimum levels of solid:solvent ratio $\left(X_{1}\right.$, range: 2 to $\left.5 \mathrm{~g} / 100 \mathrm{~mL}\right)$, extraction duration $\left(X_{2}\right.$, range: 10 to $25 \mathrm{~min}$ ), and ethanol concentration ( $X_{3}$, range: $40 \%$ to $60 \%$ ) to maximize the total phenolic content and the antioxidant activity of almond hull extract.

The extraction yield of the total phenolic content $\left(Y_{T P C}\right)$ and the antioxidant activity $\left(Y_{R S A}\right)$ against the three variables $\left(X_{1}, X_{2}\right.$, and $\left.X_{3}\right)$ were evaluated using a polynomial second-order model based on the equation used in response surface analysis to predict the optimum conditions for the extraction process:

$$
Y=\beta_{0}+\sum_{i=1}^{3} \beta_{i} X_{i}+\sum_{i=1}^{3} \beta_{i i} X_{i}^{2}+\sum_{i=1}^{2} \sum_{j=i+1}^{3} \beta_{i j} X_{i} X_{j}+\varepsilon
$$

where $Y$ represents the predicted response (TPC or RSA values), $X_{i}$ 's are the level of variables, $\beta_{0}, \beta_{i}$, $\beta_{i i}$, and $\beta_{i j}$ are the constant, linear, quadratic, and interactive terms, respectively, and $\varepsilon$ is the error.

Verification of the Model and Application

To test the accuracy of the response surface models, the values of total phenolic content and antioxidant activity calculated using the regression model were compared with those obtained from the UAE of hull extracts, carried out under optimal conditions, as determined by RSM.

Finally, the optimal conditions for UAE were applied to almond hull extracts from three Italian and four Tunisian varieties, and the yields were compared against conventional solvent extraction. The extraction procedures were performed in triplicate.

These extracts were also characterized for the levels of flavonoids and condensed tannins, and the most important phenolic compounds were determined by HPLC-DAD analysis.

\subsection{Analytical Determination}

\subsubsection{Total Phenolic Content}

The total phenolic content (TPC) of the almond hull extracts was determined in triplicate according to the Folin-Ciocalteu colorimetric method, as reported by Singleton et al. [19], with slight modifications. Briefly, $50 \mu \mathrm{L}$ of extract was mixed with $250 \mu \mathrm{L}$ of Folin-Ciocalteu reagent and $3 \mathrm{~mL}$ of ultrapure water.

The mixture was allowed to equilibrate for $3 \mathrm{~min}$ at $20^{\circ} \mathrm{C}$, and then $750 \mu \mathrm{L}$ of $20 \%(w / v)$ aqueous sodium carbonate solution was added. After incubation at $20{ }^{\circ} \mathrm{C}$ for $2 \mathrm{~h}$ in the dark, the specific absorbance of the mixture at $765 \mathrm{~nm}$ was measured with a UV-Visible spectrophotometer UV-1700 PharmaSpec (Shimadzu, Milano, Italy). A mixture of solvents and reagents was used as a blank. Gallic acid was used as a standard, and the results were expressed as mg of gallic acid equivalents (GAE) per gram of dry sample.

\subsubsection{DPPH Radical Scavenging Activity}

The free radical scavenging activity (RSA) of the extracts was determined according to the method reported by von Gadow et al. [20] using the stable radical 2,2-diphenyl-1-picrylhydrazyl radical (DPPH), 
with slight modifications. Briefly, $75 \mu \mathrm{L}$ of the sample extract were added to $3 \mathrm{~mL}$ of $6.1 \times 10^{-5} \mathrm{M}$ $\mathrm{DPPH} / \mathrm{methanol}$ solution and incubated at $20^{\circ} \mathrm{C}$ for $1 \mathrm{~h}$ in the dark. Afterwards, the decrease in absorbance at $515 \mathrm{~nm}$ was recorded using methanol as a control and DPPH/methanol solution as a blank.

The inhibition percentage (IP\%) of the DPPH by the antioxidant extracts was calculated according to the following formula

$$
I P \%=[(A B-A S) / A B] \times 100
$$

where $\mathrm{AB}$ is the absorbance of the blank and AS is the absorbance of the samples. The results were expressed as $\mu \mathrm{M}$ Trolox equivalents (TE) per gram of dry sample (dw), by means of a dose-response curve for Trolox $(0-350 \mu \mathrm{M})$.

\subsubsection{Condensed Tannin Content}

The content of condensed tannins (TCT) in the almond hull extracts was estimated using the method of Lin et al. [21], with slight modifications. An aliquot (50 $\mu \mathrm{L})$ of each extract was mixed with $3 \mathrm{~mL}$ of $4 \%$ vanillin in methanol solution, followed by the addition of $1.5 \mathrm{~mL}$ of $\mathrm{HCl}(37 \%$ v/v). The well-mixed solution was incubated at $20^{\circ} \mathrm{C}$ for $15 \mathrm{~min}$ in the dark. The absorbance of the samples was then recorded against the blank at $500 \mathrm{~nm}$. (+)-Catechin was used to prepare the calibration curve, and the results were expressed as $\mathrm{mg}$ Catechin equivalent (CE) per gram of dry sample (dw).

\subsubsection{Total Flavonoid Content}

The content of total flavonoid (TFC) in the almond hull extracts was determined following the method of Lin et al. [21], with slight modifications. Briefly, an aliquot (300 $\mu \mathrm{L})$ of each extract was mixed with $1.5 \mathrm{~mL}$ of ultra-pure water and $90 \mu \mathrm{L}$ of $5 \% \mathrm{NaNO}_{2}$ solution. After $6 \mathrm{~min}, 180 \mu \mathrm{L}$ of $10 \% \mathrm{AlCl}_{3} \times \mathrm{H}_{2} \mathrm{O}$ solution was added, and the reaction was allowed to continue for $5 \mathrm{~min}$. After the addition of $1 \mathrm{M} \mathrm{NaOH}$ solution $(600 \mu \mathrm{L})$ and $330 \mu \mathrm{L}$ of $\mathrm{H}_{2} \mathrm{O}$, the absorbance against the blank was recorded at $510 \mathrm{~nm}$. (+)-Catechin was used to construct the standard curve, and the results were expressed as $\mathrm{mg}$ Catechin equivalent (CE) per gram of sample (dw).

\subsubsection{HPLC-DAD Analysis}

Chromatographic analysis was performed according to the method described by Barbosa-Pereira et al. [22], with a Thermo-Finnigan Spectra HPLC-PDA system (Thermo-Finnigan, Waltham, USA), equipped with a P2000 binary gradient pump, a SCM 1000 degasser, an AS 3000 automatic injector, and a Finnigan Surveyor PDA Plus detector. The compounds were separated on a Kinetex Phenyl-Hexyl C18 column $(150 \times 4.6 \mathrm{~mm}$ internal diameter and 5- $\mu \mathrm{m}$ particle size) (Phenomenex, Castel Maggiore, Italy) with the thermostat at $35^{\circ} \mathrm{C}$. The two solvents used for the mobile phase were $0.1 \%(v / v)$ formic acid in water (solvent $\mathrm{A}$ ) and $100 \%$ methanol (solvent B). The flow of the mobile phase was set at $1 \mathrm{~mL} / \mathrm{min}$ and the injection volume was $10 \mu \mathrm{L}$. A gradient elution method was applied, starting with a 90\% mobile phase composition of (A), maintained isocratically for 2 min. It was reduced to $50 \%$ after $30 \mathrm{~min}, 20 \%$ after $40 \mathrm{~min}$, and finally, to $10 \%$ after $42 \mathrm{~min}$. PDA spectra were recorded using a full scan modality over a wavelength $(\lambda)$ range of 200 to $550 \mathrm{~nm}$, and data were quantified using the external standard method with six-point calibration curves. The system and data acquisition were managed by the Chrom Quest software (version 5.0, Thermo-Finnigam, Waltham, USA). For the quantification, a calibration curve was prepared for each identified compound.

\subsubsection{Statistical Analysis}

The Design-Expert ${ }^{\circledR}$ software version 13 (Stat-Ease, Inc., Minneapolis, MN, USA) was used to perform the Central Composite Design with multiple regression analysis and analysis of variance (ANOVA) of the experimental data. 
The adequacy of the fitted model was determined by evaluating the lack of fit and the coefficient of determination $\left(\mathrm{R}^{2}\right)$. The significance of each coefficient was determined using an F-test.

A response surface methodology (RSM) with a Box-Behnken design was used for the optimization of the processing parameters and to study the effect of individual factors and their interactive effects. The polyphenol concentration of hull extracts from Italian and Tunisian varieties was compared by analysis of variance, followed by a Duncan's multiple range test with Statistica ver. 13 (StatSoft Inc., Tulsa, OK, USA).

\section{Results and Discussion}

\subsection{Selection range of $C C D$}

The range for each CCD variable (solid:solvent ratio, extraction time and ethanol concentration) was determined based on a preliminary test, where UAE was applied to almond hulls of the Zahaf variety and the TPC yield was evaluated (Table 1).

Table 1. Results of single-factor experiments for ultrasound-assisted extraction from almond hull of Zahaf variety and results of ANOVA with Duncan's test. Values are reported as means \pm standard deviation of two extractions.

\begin{tabular}{|c|c|c|c|c|c|}
\hline $\begin{array}{l}\text { Solid:Solvent } \\
\text { Ratio (g/100mL) }\end{array}$ & $\begin{array}{c}\text { TPC } \\
\left(\mathrm{mg}_{\mathrm{GAE}} / \mathrm{g}_{\mathrm{dw}}\right)\end{array}$ & $\begin{array}{l}\text { Extraction } \\
\text { Time (min) }\end{array}$ & $\begin{array}{c}\text { TPC } \\
\left(\mathrm{mg}_{\mathrm{GAE}} / \mathrm{g}_{\mathrm{dw}}\right)\end{array}$ & $\begin{array}{c}\text { Ethanol } \\
\text { Concentration }(\% v / v)\end{array}$ & $\begin{array}{c}\text { TPC } \\
\left(\mathrm{mg}_{\mathrm{GAE}} / \mathrm{g}_{\mathrm{dw}}\right)\end{array}$ \\
\hline 2 & $6.44 \pm 0.25$ & 1 & $5.05 \pm 0.11^{\mathrm{a}}$ & 20 & $4.47 \pm 0.09^{b}$ \\
\hline 2.5 & $6.37 \pm 0.44$ & 5 & $5.81 \pm 0.24^{b}$ & 40 & $7.69 \pm 0.13^{d}$ \\
\hline 3.3 & $6.52 \pm 0.46$ & 10 & $6.22 \pm 0.06^{b}$ & 60 & $6.52 \pm 0.47^{c}$ \\
\hline 5 & $6.28 \pm 0.14$ & 15 & $6.52 \pm 0.47^{c}$ & 80 & $3.77 \pm 0.14^{b}$ \\
\hline \multirow[t]{3}{*}{10} & $6.02 \pm 0.27$ & 20 & $6.64 \pm 0.13^{c}$ & 100 & $0.49 \pm 0.01^{\mathrm{a}}$ \\
\hline & & 25 & $6.87 \pm 0.13^{c}$ & & \\
\hline & & 30 & $6.75 \pm 0.29^{c}$ & & \\
\hline Significance & $\mathrm{ns}$ & & $* *$ & & $* * *$ \\
\hline
\end{tabular}

The TPC of extracts first increased and then reduced with increasing ethanol concentration, with the maximum value $\left(7.69 \mathrm{mg}_{\mathrm{GAE}} / \mathrm{g}_{\mathrm{dw}}\right)$ obtained at $40 \%$ ethanol aqueous solution. These results are in agreement with those reported by Pan et al. [23], Spigno et al. [24], and Liu et al. [25], who observed the same effect of ethanol concentration on the TPC of extracts obtained from plant materials. In particular, the TPC values of extracts from black goji berry increased slightly with ethanol concentrations of up to $70 \%$, and then decreased [26]. The maximum value obtained was $17.9 \mathrm{mg}_{\mathrm{GAE}} / \mathrm{g}_{\mathrm{dw}}$ at $70 \%$ concentration. A similar effect was reported for sunflower seed cake [9], wheat bran [27], black currants [28], and jackfruit peel [29] extracts. This phenomenon could be explained by the fact that the solvent polarity and molecular movement decrease with increasing ethanol concentration, leading to a low dissolution of phenolic compounds via the lowering of the diffusion coefficient and decreased solubility $[30,31]$. Furthermore, water and low-concentration ethanol can easily pass through the cell membranes, whereas a high ethanol concentration can cause protein denaturation, preventing the dissolution of phenolics [32]. Therefore, ethanol concentrations of up to $60 \%$ were suitable for the extraction of phenolics. Moreover, the extraction duration significantly affected the TPC values, and an increase was observed when the extraction duration was increased from 1 to $25 \mathrm{~min}$, followed by a decrease thereafter. These results are in agreement with that of He et al. [26], who reported that the TPC values of extract from black goji berry, obtained by accelerated solvent extractor, increased with increasing the extraction duration until $11 \mathrm{~min}$, and then decreased. As the TPC values increase up to $25 \mathrm{~min}$ and a shorter extraction duration also helps reduce energy costs, 
the 10-25 min range was selected for the RSM trials. Lastly, the TPC values showed no significant difference with changing the solid:solvent ratio, which is in contrast to the findings of Spigno et al. [24]. These authors observed that an increase in the solid:solvent ratio could lead to an increase in the extraction efficiency via increasing the concentration gradient, which causes the mass transfer from the solvent impregnated on the solid particles into the external solvent.

According to the obtained results, the selected range for the solid:solvent ratio was 2 to $5 \mathrm{~g} / 100 \mathrm{~mL}$, for the extraction time was 10 to $25 \mathrm{~min}$, and for ethanol concentration was $40 \%$ to $60 \%$. The selected range for each processing parameter and corresponding coded value are reported in Table 2.

Table 2. Values and coded levels of the independent variables for central composite design used for almond hull extraction.

\begin{tabular}{ccccccc}
\hline \multirow{2}{*}{ Independent Variables } & \multirow{2}{*}{ Code } & \multicolumn{5}{c}{ Coded Variable Levels } \\
\cline { 3 - 7 } & & $\mathbf{- 1 . 6 8 1 8}$ & $\mathbf{- 1}$ & $\mathbf{0}$ & $\mathbf{1}$ & $\mathbf{1 . 6 8 1 8}$ \\
\hline Solid:solvent ratio $(\mathrm{g} / 100 \mathrm{~mL})$ & $X_{1}$ & 2 & 2.6 & 3.5 & 4.4 & 5 \\
\hline Extraction Time $(\mathrm{min})$ & $X_{2}$ & 10 & 13 & 18 & 22 & 25 \\
\hline Ethanol concentration $(\%, v / v)$ & $X_{3}$ & 40 & 44 & 50 & 56 & 60 \\
\hline
\end{tabular}

\subsection{Optimization of UAE parameters}

Experimental values of TPC and RSA of almond hulls extracts obtained using UAE are shown in Table 3.

Table 3. Composite design and values of total phenolic content (TPC) and radical scavenging activity (RSA) for extracts obtained from almond hull with UAE. Data are reported as means \pm standard deviation.

\begin{tabular}{|c|c|c|c|c|c|}
\hline \multirow{2}{*}{ Runs } & \multicolumn{3}{|c|}{ Uncoded Variables } & \multicolumn{2}{|c|}{ Responses } \\
\hline & $X_{1}(\mathrm{~g} / 100 \mathrm{~mL})$ & $X_{2}(\min )$ & $X_{3}(\%, v / v)$ & TPC (mgGAE $\left./ g_{d w}\right)$ & $\operatorname{RSA}\left(\mu \mathbf{M}_{\mathrm{TE}} / \mathbf{g}_{\mathrm{dw}}\right)$ \\
\hline 1 & 2.0 & 18 & 50 & $7.25 \pm 0.08$ & $55.30 \pm 2.74$ \\
\hline 2 & 2.6 & 13 & 44 & $6.90 \pm 0.11$ & $50.6 \pm 2.09$ \\
\hline 3 & 2.6 & 13 & 56 & $6.72 \pm 0.11$ & $49.82 \pm 2.56$ \\
\hline 4 & 2.6 & 22 & 44 & $7.22 \pm 0.07$ & $47.54 \pm 1.77$ \\
\hline 5 & 2.6 & 22 & 56 & $7.28 \pm 0.16$ & $49.88 \pm 0.31$ \\
\hline 6 & 3.5 & 10 & 50 & $7.07 \pm 0.05$ & $44.29 \pm 0,56$ \\
\hline 7 & 3.5 & 18 & 40 & $7.71 \pm 0.10$ & $44.56 \pm 1.13$ \\
\hline 8 & 3.5 & 18 & 60 & $7.02 \pm 0.40$ & $39.87 \pm 1.35$ \\
\hline 9 & 3.5 & 25 & 50 & $7.61 \pm 0.15$ & $44.23 \pm 2.29$ \\
\hline 10 & 4.4 & 13 & 44 & $6.95 \pm 0.26$ & $38.0 \pm 1.63$ \\
\hline 11 & 4.4 & 13 & 56 & $6.95 \pm 0.26$ & $37.57 \pm 1.63$ \\
\hline 12 & 4.4 & 22 & 44 & $8.03 \pm 0.06$ & $44.41 \pm 1.60$ \\
\hline 13 & 4.4 & 22 & 56 & $7.66 \pm 0.30$ & $39.19 \pm 1.61$ \\
\hline 14 & 5.0 & 18 & 50 & $7.71 \pm 0.29$ & $39.57 \pm 0.76$ \\
\hline 15 & 3.5 & 18 & 50 & $7.94 \pm 0.21$ & $47.8 \pm 2.31$ \\
\hline 16 & 3.5 & 18 & 50 & $8.09 \pm 0.02$ & $48.00 \pm 2.96$ \\
\hline 17 & 3.5 & 18 & 50 & $8.01 \pm 0.22$ & $47.82 \pm 1.62$ \\
\hline 18 & 3.5 & 18 & 50 & $8.02 \pm 0.21$ & $50.32 \pm 1.57$ \\
\hline 19 & 3.5 & 18 & 50 & $7.88 \pm 0.06$ & $46.09 \pm 1.53$ \\
\hline 20 & 3.5 & 18 & 50 & $8.06 \pm 0.25$ & $46.49 \pm 1.89$ \\
\hline
\end{tabular}


The mean TPC values ranged from 6.72 to $8.09 \mathrm{mg}_{\mathrm{GAE}} / \mathrm{g}_{\mathrm{dw}}$, while the mean of RSA values ranged from 37.57 to $55.30 \mu \mathrm{M}_{\mathrm{TE}} / \mathrm{g}_{\mathrm{dw}}$.

The use of UAE improved the extraction yield by up to $225 \%$ for TPC and $150 \%$ for the RSA compared with control tests performed with the conventional solid-solvent extraction. The use of UAE allowed us to significantly reduce the time of extraction, i.e., from $6 \mathrm{~h}$ to less than $30 \mathrm{~min}$, avoiding the use of temperature that may decrease the extraction yield of polyphenols which are sensitive to degradation at high temperatures, and reducing the costs of the procedure in a potential application at the industrial level.

The data obtained from the central composite design were fitted to second-order polynomial equations, and the significance of the model coefficients was determined by the ANOVA test. The coefficients and corresponding $p$ values for each variable are shown in Table 4 .

Table 4. Analysis of variance of second-order polynomial models for the total phenolic content (TPC) and the radical scavenging activity (RSA) determined on almond hull extracts obtained using UAE.

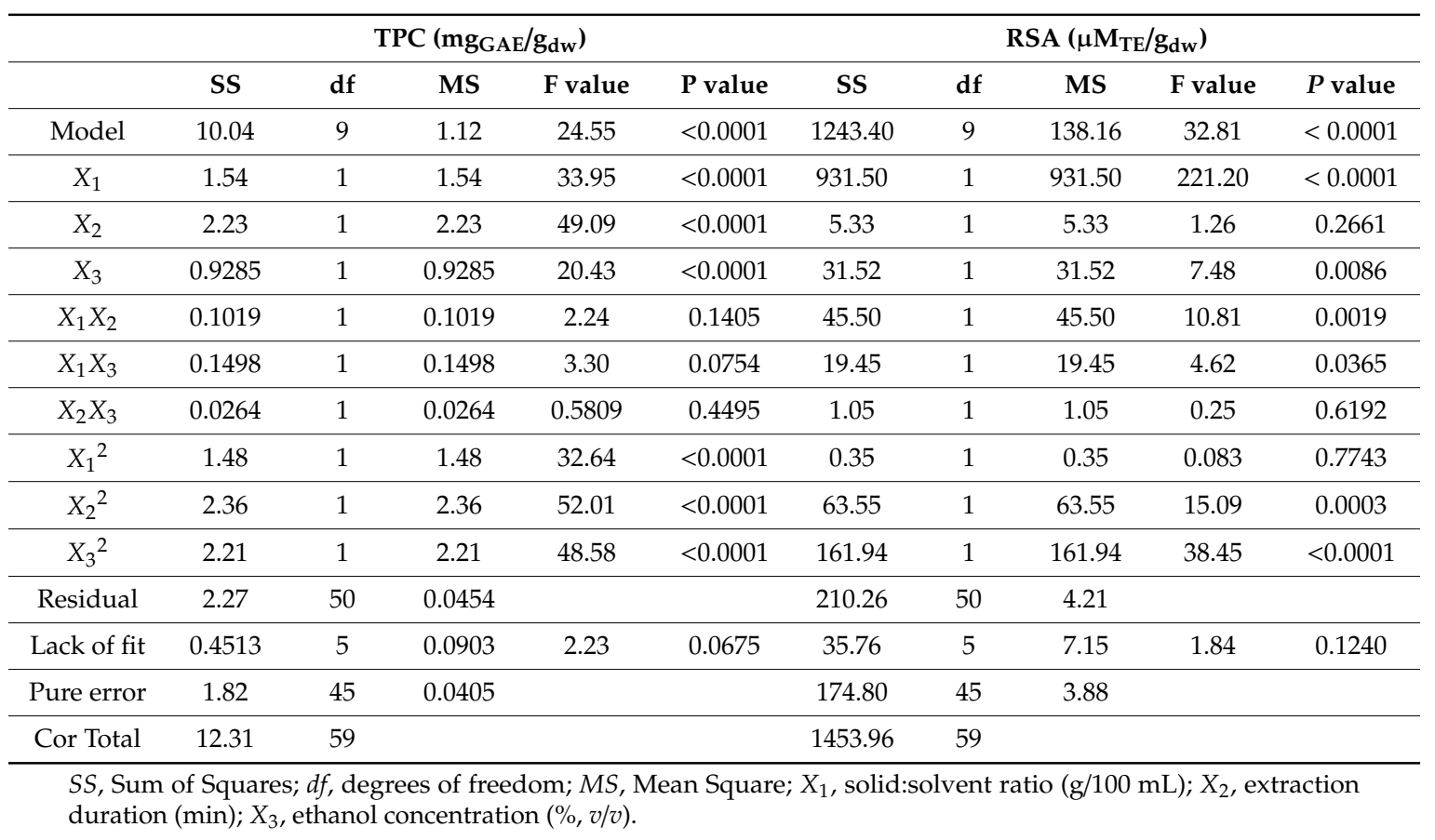

High $F$ values ( 24.55 for TPC and 32.81 for RSA) with very low $p$ values suggest that the fitted model was statistically significant, demonstrating that the TPC and RSA values could be well predicted with the variable ranges used in the model.

The lack of fit was nonsignificant $(p>0.05)$ for both the parameters, confirming that the model adequately reflected the experimental results.

For TPC, the model obtained by RSM had $\mathrm{R}^{2}=0.8155, \mathrm{R}^{2} \mathrm{Adj}=0.7823$, and $\mathrm{CV} \%=2.84$. For the RSA, the model had $R^{2}=0.8552, R^{2}$ Adj $=0.8291$, and $C V \%=4.50$. Therefore, a good degree of correlation between the observed and the predicted values was observed for both parameters. Moreover, the low value of coefficient of variation demonstrated a high degree of precision and a good level of reliability of the results.

The quadratic polynomial equations for TPC and RSA (expressed with real values) are presented in Equations (4) and (5), respectively:

$$
\begin{gathered}
\mathrm{TPC}=-15.39+2.30 X_{1}+0.34 X_{2}+0.64 X_{3}+0.0164 X_{1} X_{2}-0.0149 X_{1} X_{3}+0.00125 X_{2} X_{3} \\
-0.23 X_{1}^{2}-0.12 X_{2}^{2}-0.00639 X_{3}^{2}
\end{gathered}
$$




$$
\begin{gathered}
\text { RSA }=-99.86-2.12 X_{1}+1.397 X_{2}-6.058 X_{3}+0.346 X_{1} X_{2}-0.169 X_{1} X_{3}-0.00789 \\
X_{2} X_{3}-0.113 X_{1}{ }^{2}-0.061 X_{2}{ }^{2}-0.0547 X_{3}{ }^{2}
\end{gathered}
$$

The solid:solvent ratio, extraction duration, and ethanol concentration had significant linear and quadratic effects on TCP values, while only the solid:solvent ratio and ethanol concentration had significant linear effects on RSA values. The quadratic effects of extraction duration and ethanol concentration are also significant for RSA values. Generally, the interactions between two variables were not significant, except for RSA $\left(X_{1} X_{2}\right.$ and $\left.X_{2} X_{3}\right)$. The relationships between independent variables and TPC or RSA values were illustrated by a three-dimensional representation of the response surface (Figure 1a-f).

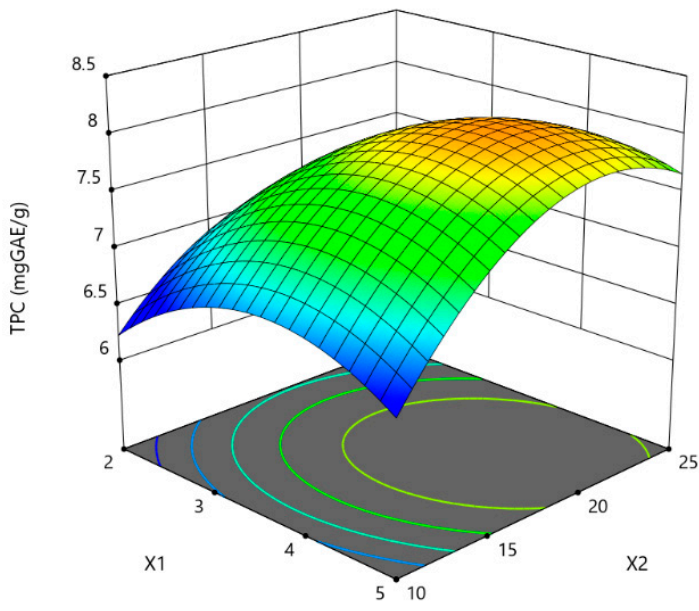

(a)

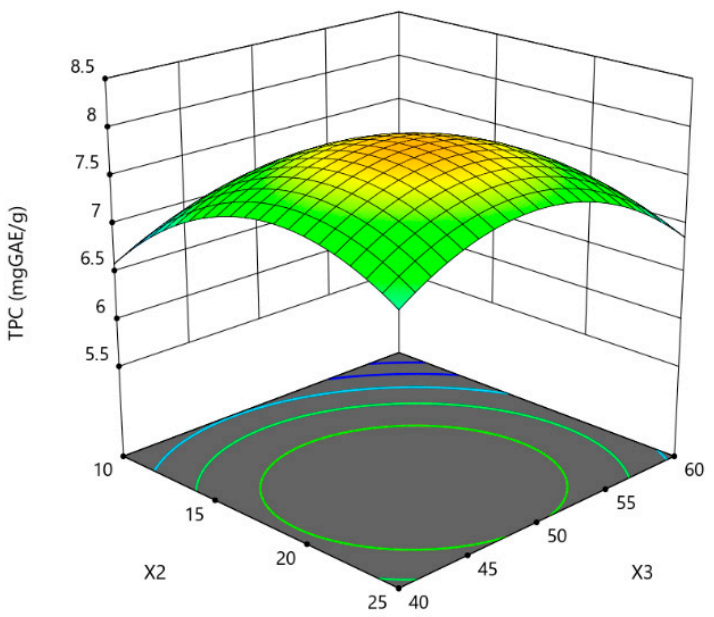

(c)

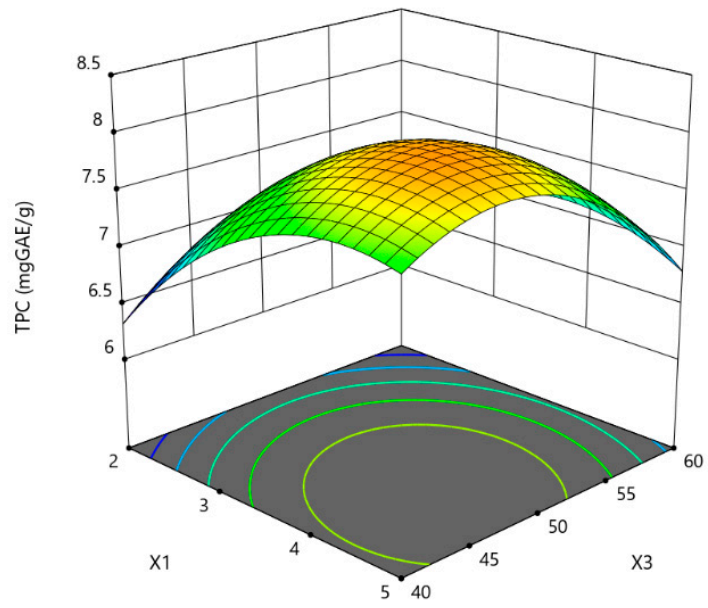

(b)

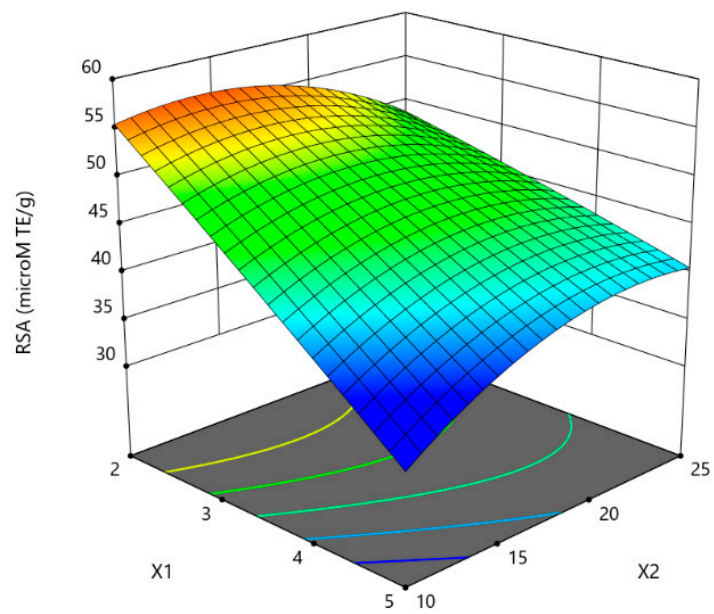

(d)

Figure 1. Cont. 


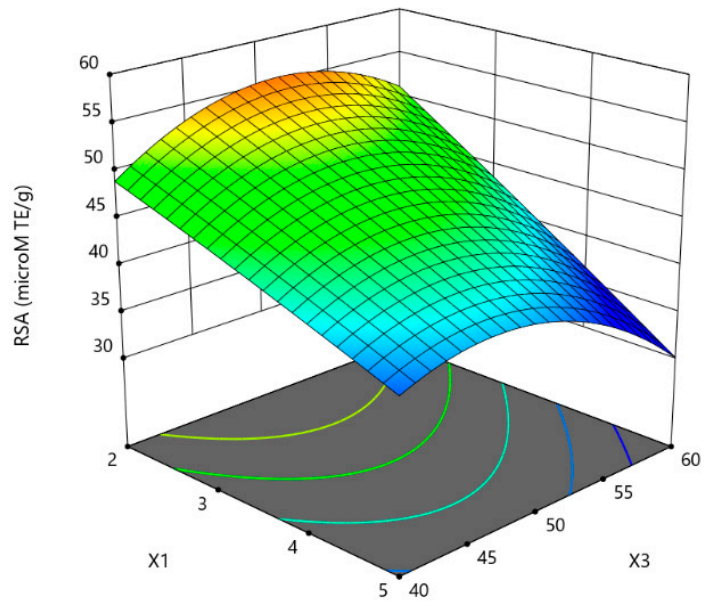

(e)

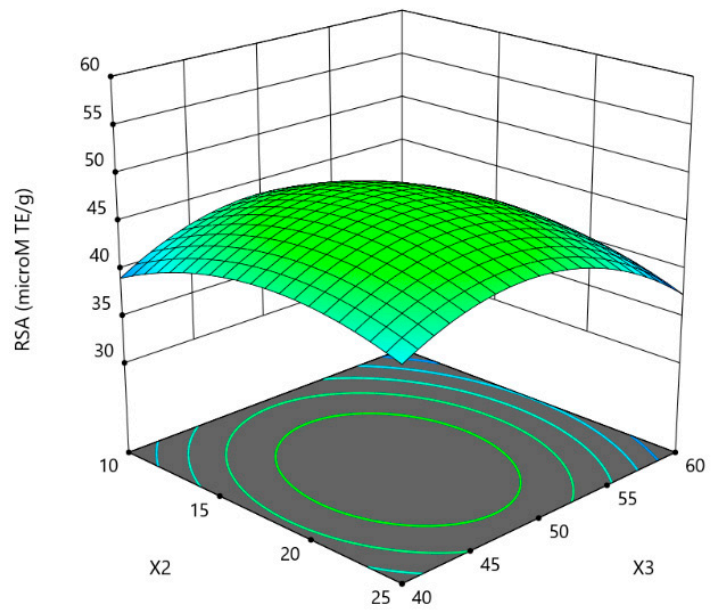

(f)

Figure 1. Response surface plots showing the effect of interaction of solid:solvent ratio $\left(X_{1} ; g / 100 \mathrm{~mL}\right)$, extraction duration $\left(X_{2} ; \mathrm{min}\right)$, and ethanol concentration $\left(X_{3} ; \% v / v\right)$ on TPC $(\mathbf{a}-\mathbf{c})$ and RSA (d-f) values of almond hull extracts obtained using UAE. For each graph, the third variable was fixed at the central value.

The graphs showed that high values of TPC (Figure 1a-c) and RSA (Figure 1d-f) for almond hull extracts with UAE could be obtained by using low-medium values of solid:solvent ratio and a medium extraction duration using an ethanol concentration of $50 \%$, or by using a low ethanol concentration with long extraction durations. In depth, higher TPC yields can be achieved with moderate-high solid:solvent ratios, using medium-high values of extraction times and intermediate values of ethanol concentration.

These results are in accordance with those reported by Carini et al. [33], Juntachote et al. [34], and Yang et al. [30], who observed that high extraction durations significantly increased the extraction yield of polyphenols, likely due to an increase in the mass transfer of phenolic compounds and a reduction in solvent viscosity and surface tension. Instead, for RSA, higher values were observed using lower solid:solvent ratios and lower extraction times with respect to the TPC. The results highlighted that the main phenolic compounds responsible for the radical scavenging activity of the extracts can be yield under the RSA optimal conditions using lower solid-solvent ratios and lower extraction times. Therefore, under these conditions, more active extracts from almond hulls can be achieved in a sustainable process at room temperature, making it economically feasible for implementation on an industrial scale.

\subsection{Determination of the Optimal Conditions and Validation of the Model}

A desirability function approach of Design Expert ver. 11.0 was used to determine the optimum conditions of solid:solvent ratio, extraction time, and ethanol concentration in order to obtain the highest values for TPC and RSA of almond hull extracts obtained with UAE. The values observed were as follows: solid:solvent ratio of $2 \mathrm{~g} / 100 \mathrm{~mL}$, extraction duration of $13.86 \mathrm{~min}$, and an ethanol concentration of $51.2 \% v / v$. Under these conditions, the predicted values were $6.81 \mathrm{mg}_{\mathrm{GAE}} / \mathrm{g}_{\mathrm{dw}}$ and $56.4 \mu \mathrm{M}_{\mathrm{TE}} / \mathrm{g}_{\mathrm{dw}}$ for TPC and RSA, respectively. A new set of extractions of Zahaf hulls was then performed using UAE, and the obtained experimental values for were $8.30 \pm 0.69 \mathrm{mg}_{\mathrm{GAE}} / \mathrm{g}_{\mathrm{dw}}$ for TPC and $60.53 \pm 2.89 \mu \mathrm{M}_{\mathrm{TE}} / \mathrm{g}_{\mathrm{dw}}$ for RSA, which confirmed that the model was satisfactory and accurate. 


\subsection{Polyphenolic Content and Antioxidant Capacity of Almond Hulls Extracts}

The optimized extraction procedure was applied to the almond hulls of three Italian and four Tunisian varieties, and the obtained results were compared with those of traditional solvent extraction.

All almond hull extracts were analyzed for total phenolic compounds (TPC), flavonoids, and tannins, as well as the radical scavenging activity; the results are reported in Table 5.

Table 5. Mean values $(n=3)$ and standard deviation of radical scavenging activity (RSA) and total phenolic content (TPC), total flavonoid content (TFC), and total condensed tannins (TCT) in extracts obtained using ultrasound-assisted extraction (UAE) and conventional solvent extraction (CSE) of almond hull samples. For each analytical parameter, an analysis of variance with Duncan's test was performed to compare the varieties and the two extraction methods.

\begin{tabular}{|c|c|c|c|c|c|c|}
\hline & \multicolumn{3}{|c|}{$\mathrm{TPC}\left(\mathrm{mg}_{\mathrm{GAE}} / \mathrm{g}_{\mathrm{dw}}\right)$} & \multicolumn{3}{|c|}{ TCT $\left(\mathrm{mg}_{\mathrm{CE}} / \mathrm{g}_{\mathrm{dw}}\right)$} \\
\hline & UAE & CSE & Significance & UAE & CSE & Significance \\
\hline Pizzuta & $210.49 \pm 1.79^{\mathrm{d}}$ & $31.98 \pm 12.05^{\mathrm{c}}$ & $* * *$ & $123.54 \pm 2.8^{\mathrm{d}}$ & $23.54 \pm 11.59^{c}$ & $* * *$ \\
\hline Fascionello & $146.47 \pm 5.83^{b c}$ & $19.78 \pm 1.69^{b}$ & $* * *$ & $80.21 \pm 0.62^{c}$ & $9.62 \pm 0.53^{b}$ & $* * *$ \\
\hline Romana & $160.03 \pm 25.44^{c}$ & $25.66 \pm 5.55^{b}$ & $* * *$ & $74.36 \pm 5.78^{b}$ & $13.11 \pm 3.39^{b}$ & $* * *$ \\
\hline Achaak & $138.70 \pm 4.52^{b c}$ & $24.23 \pm 4.57^{\mathrm{b}}$ & $* * *$ & $81.34 \pm 1.01^{\mathrm{c}}$ & $11.30 \pm 2.98^{b}$ & $* * *$ \\
\hline Fakhfekh & $207.77 \pm 4.23^{\mathrm{d}}$ & $25.79 \pm 4.04^{b}$ & $* * *$ & $123.49 \pm 4.40^{\mathrm{d}}$ & $15.20 \pm 2.71 \mathrm{bc}$ & $* * *$ \\
\hline Laurane & $133.69 \pm 5.89^{b}$ & $16.32 \pm 2.21^{b}$ & $* * *$ & $70.76 \pm 1.33^{b}$ & $8.73 \pm 1.36^{b}$ & $* * *$ \\
\hline Zahaf & $8.37 \pm 0.83^{\mathrm{a}}$ & $3.08 \pm 0.09^{a}$ & $* *$ & $1.78 \pm 0.22^{\mathrm{a}}$ & $0.09 \pm 0.02^{\mathrm{a}}$ & $* *$ \\
\hline \multirow[t]{3}{*}{ Significance } & $* * *$ & $*$ & & $* * *$ & * & \\
\hline & \multicolumn{3}{|c|}{ TFC (mgCE/gdw) } & \multicolumn{3}{|c|}{$\operatorname{RSA}\left(\mu \mathrm{M}_{\mathrm{TE}} / \mathrm{g}_{\mathrm{dw}}\right)$} \\
\hline & UAE & CSE & Significance & UAE & CSE & Significance \\
\hline Pizzuta & $117.77 \pm 4.84^{\mathrm{d}}$ & $16.83 \pm 7.99^{c}$ & $* * *$ & $1938.07 \pm 18.69^{d}$ & $183.62 \pm 25.22 \mathrm{~cd}$ & $* * *$ \\
\hline Fascionello & $80.29 \pm 4.17 \mathrm{bc}$ & $9.07 \pm 0.74^{b}$ & $* * *$ & $1606.83 \pm 62.92^{c}$ & $142.97 \pm 10.44^{\mathrm{bc}}$ & $* * *$ \\
\hline Romana & $73.37 \pm 2.77^{b}$ & $12.36 \pm 3.56^{\mathrm{bc}}$ & $* * *$ & $1565.18 \pm 42.14^{\mathrm{c}}$ & $168.96 \pm 22.90^{c}$ & $* * *$ \\
\hline Achaak & $81.29 \pm 4.48^{c}$ & $11.17 \pm 3.14^{b c}$ & $* * *$ & $\begin{array}{c}1450.47 \pm \\
131.03^{\mathrm{b}}\end{array}$ & $167.74 \pm 26.50^{c}$ & $* * *$ \\
\hline Fakhfekh & $120.04 \pm 4.96^{\mathrm{d}}$ & $12.65 \pm 2.52^{b c}$ & $* * *$ & $1990.78 \pm 39.58^{d}$ & $203.43 \pm 8.72^{d}$ & $* * *$ \\
\hline Laurane & $77.30 \pm 3.04^{b c}$ & $7.19 \pm 1.45^{\mathrm{ab}}$ & $* * *$ & $1607.18 \pm 36.74^{c}$ & $129.49 \pm 12.32^{b}$ & $* * *$ \\
\hline Zahaf & $3.08 \pm 0.28^{\mathrm{a}}$ & $0.87 \pm 0.04^{\mathrm{a}}$ & $* *$ & $64.83 \pm 3.04^{\mathrm{a}}$ & $23.43 \pm 7.36^{\mathrm{a}}$ & $* * *$ \\
\hline Significance & $* * *$ & $*$ & & $* * *$ & $* * *$ & \\
\hline
\end{tabular}

The use of UAE significantly improved the extraction of phenolics compared to conventional extraction in all almond hull samples studied. The increases in the TPC, TCT, and TFC values observed in the extracts of the various tested samples were up to 2.7-8.2, 5.2-19.0, and 3.5-10.8 times higher, respectively, compared with extracts yielded using the conventional extraction. The increase effect was more evident for samples such as Fascionello, Fakhfekh, and Laurane. The RSA results followed the same tendency as the different groups of polyphenols, and the values observed were up to 2.8-12.4 times higher than the extracts yielded using the conventional extraction. In this case, the Pizutta, Fascionello, and Laurane samples showed a high increase in antioxidant capacity using UAE.

Previous studies have reported that the use of UAE for almond hull extracts improves the extraction yield of polyphenols and the antioxidant activity by up to approximately three times compared with conventional solvent extraction. Examples of these studies include those by Zardo et al. [9], who use the UAE for polyphenol extraction from sunflower seed cake, Hifza et al. [35], who applied UAE for oil extraction, reporting an increment of about $2 \%$ compared with conventional Soxhlet extraction, and Ryu and Koh [36], who observed that the highest value was obtained at 18 min for UAE, compared 
with the conventional solvent extraction duration of $30 \mathrm{~min}$. In the present study, the extraction yield of the different compounds was significantly improved compared to previous studies.

Hull extracts from Pizzuta and Fakhfekh varieties displayed the highest content of polyphenolic compounds (210.49 mg $\mathrm{GAE}_{\mathrm{GA}} / \mathrm{g}_{\mathrm{dw}}$ and $207.77 \mathrm{mg}_{\mathrm{GAE}} / \mathrm{g}_{\mathrm{dw}}$, respectively), whereas Zahaf showed the lowest $\left(8.37 \mathrm{mg}_{\mathrm{GAE}} / \mathrm{g}_{\mathrm{dw}}\right)(p<0.05)$. Pinelo et al. [37] reported that ethanol was the optimal solvent for polyphenol extraction in almond hull; they determined the TPC of 12 almond hull samples using this solvent. The values reported by these authors ranged from 23 to $61 \mathrm{mg}_{\mathrm{GAE}} / \mathrm{g}_{\mathrm{dw}}$, which were lower than those obtained in the current study. Subhashinee et al. [38] also found a lower polyphenol content $\left(71.1 \mathrm{mg}_{\mathrm{GAE}} / \mathrm{g}_{\mathrm{dw}}\right)$ in almond green cover shell extract using a traditional solvent extraction with $80 \%$ $(v / v)$ ethanol.

The highest flavonoid content was obtained from hull extracts of Fakhfekh $\left(120.04 \mathrm{mg} \mathrm{CE}_{\mathrm{C}} / \mathrm{g}_{\mathrm{dw}}\right)$ and Pizzuta varieties $\left(117.77 \mathrm{mg} \mathrm{CE}_{\mathrm{C}} / \mathrm{g}_{\mathrm{dw}}\right)$, whereas the lowest values were observed for Laurane (77.3 $\left.\mathrm{mg}_{\mathrm{CE}} / \mathrm{g}_{\mathrm{dw}}\right)$ and Zahaf $\left(3.08 \mathrm{mg}_{\mathrm{CE}} / \mathrm{g}_{\mathrm{dw}}\right)$ hull extracts.

A similar trend was observed for condensed tannins, where the highest content was observed for Pizzuta $\left(123.54 \mathrm{mg}_{\mathrm{CE}} / \mathrm{g}_{\mathrm{dw}}\right)$ and Fakhfekh $\left(123.49 \mathrm{mg}_{\mathrm{CE}} / \mathrm{g}_{\mathrm{dw}}\right)$ extracts, whereas the lowest content was obtained for Zahaf hull extracts $\left(1.78 \mathrm{mg}_{\mathrm{CE}} / \mathrm{g}_{\mathrm{dw}}\right)$.

These results highlighted that factors as genotype, cultivation techniques, and climatic conditions may also affect the polyphenolic content in almond hulls, as except for Fakhfekh, the Italian almond varieties showed higher polyphenolic contents than the Tunisian varieties.

The hull samples from Fakhfekh and Pizzuta varieties exhibited the highest RSA values $\left(1990.78 \mu \mathrm{M}_{\mathrm{TE}} / \mathrm{g}_{\mathrm{dw}}\right.$ and $1938.07 \mu \mathrm{M}_{\mathrm{TE}} / \mathrm{g}_{\mathrm{dw}}$, respectively), whereas Zahaf showed the lowest $\left(64.83 \mu \mathrm{M}_{\mathrm{TE}} / \mathrm{g}_{\mathrm{dw}}\right)$. The hull samples from Fakhfekh and Pizzuta varieties exhibited the highest RSA values (1990.78 $\mu \mathrm{M}_{\mathrm{TE}} / \mathrm{g}_{\mathrm{dw}}$ and $1938.07 \mu \mathrm{M}_{\mathrm{TE}} / \mathrm{g}_{\mathrm{dw}}$, respectively), whereas Zahaf showed the lowest $\left(64.83 \mu \mathrm{M}_{\mathrm{TE}} / \mathrm{g}_{\mathrm{dw}}\right)$.

\subsection{Identification and Quantification of Polyphenolic Compounds}

The HPLC analysis of the extracts highlighted the presence of seven compounds identified by comparison with analytical standards (Table 6). The main phenolic compounds identified and quantified in the several almond hull samples are shown in Table 7. Chlorogenic acid, catechin, and protocatechuic acid were found in all varieties, as were the major phenolic compounds identified in almond hull extracts. Other polyphenols, including quercetin-3-glucoside, p-coumaric acid, and epicatechin were also identified, but only in extracts obtained using UAE, and generally, from Italian almond varieties.

Table 6. Retention time (Rt), detection wavelength $(\lambda \max )$, linear equation, investigated linear range, determination coefficient $\left(r^{2}\right)$, linear range, LOD, and LOQ of the phenolic compound standards.

\begin{tabular}{cccccccc}
\hline Compound & Rt $(\mathbf{m i n})$ & $\lambda_{\max }(\mathbf{n m})$ & $\begin{array}{c}\text { Linear Range } \\
(\mathbf{m g} / \mathbf{L})\end{array}$ & Linear Equation & $r^{2}$ & $\begin{array}{c}\text { LOD } \\
(\mathbf{m g} / \mathbf{L})\end{array}$ & $\begin{array}{c}\text { LOQ } \\
(\mathbf{m g} / \mathbf{L})\end{array}$ \\
\hline Protocatechuic acid & 4.36 & 293 & $0.2-202$ & $y=78697 x+19672$ & 0.9997 & 0.1 & 0.2 \\
\hline Catechin & 8.7 & 279 & $0.5-194$ & $y=32326 x-13902$ & 0.9999 & 0.2 & 0.5 \\
\hline Caffeic acid & 10.87 & 325 & $0.2-23.6$ & $y=234675 x-53489$ & 0.9997 & 0.1 & 0.2 \\
\hline Chlorogenic acid & 11.54 & 325 & $0.5-119$ & $y=116431 x+47158$ & 0.9996 & 0.2 & 0.5 \\
\hline Epicatechin & 13.48 & 279 & $0.5-198$ & $y=31724 x+35810$ & 0.9998 & 0.2 & 0.5 \\
\hline p-Coumaric acid & 16.34 & 325 & $0.2-113$ & $y=178167 x+12076$ & 0.9999 & 0.1 & 0.2 \\
\hline Quercetin-3-glucoside & 24.36 & 355 & $0.5-110.0$ & $y=84895 x+14596$ & 0.9996 & 0.1 & 0.5 \\
\hline
\end{tabular}


Table 7. Mean value $(n=3)$ and standard deviation of polyphenolic compounds $\left(\mathrm{mg} / \mathrm{g}_{\mathrm{dw}}\right)$ identified and quantified by HPLC-DAD in almond hull extracts obtained using UAE and CSE, and the results of the analysis of variance with a Duncan's test, between the varieties and the two extraction methods.

\begin{tabular}{|c|c|c|c|c|c|c|}
\hline & \multicolumn{3}{|c|}{ Quercetin-3-glucoside } & \multicolumn{3}{|c|}{ p-coumaric acid } \\
\hline & UAE & CSE & Significance & UAE & CSE & Significance \\
\hline Pizzuta & $0.02 \pm 0.00^{b}$ & nd & $* * *$ & $0.03 \pm 0.01^{b}$ & nd & $* * *$ \\
\hline Fascionello & $0.003 \pm 0.01^{\mathrm{ab}}$ & nd & $* * *$ & $0.006 \pm 0.01^{\mathrm{a}}$ & nd & $* * *$ \\
\hline Romana & $0.006 \pm 0.01^{\mathrm{a}}$ & nd & $* *$ & nd & nd & \\
\hline Achaak & nd & nd & & nd & nd & \\
\hline Fakhfekh & nd & nd & & nd & nd & \\
\hline Laurane & nd & nd & & nd & nd & \\
\hline Zahaf & nd & nd & & nd & nd & \\
\hline \multirow[t]{3}{*}{ Significance } & $* *$ & & & $* *$ & & \\
\hline & \multicolumn{3}{|c|}{ Chlorogenic acid } & Epicatechin & & \\
\hline & UAE & CSE & Significance & UAE & CSE & Significance \\
\hline Pizzuta & $4.76 \pm 0.25^{\mathrm{e}}$ & $0.12 \pm 0.09^{b}$ & $* * *$ & $0.03 \pm 0.00^{b}$ & nd & $* * *$ \\
\hline Fascionello & $1.60 \pm 0.12^{\mathrm{d}}$ & $0.003 \pm 0.001^{\mathrm{a}}$ & $* * *$ & $0.006 \pm 0.01^{\mathrm{a}}$ & nd & $* * *$ \\
\hline Romana & $0.67 \pm 0.24^{b}$ & nd & $* * *$ & nd & nd & \\
\hline Achaak & $1.25 \pm 0.08^{c}$ & nd & $* * *$ & nd & nd & \\
\hline Fakhfekh & $3.35 \pm 0.07^{\mathrm{e}}$ & $0.006 \pm 0.01^{a}$ & $* * *$ & nd & nd & \\
\hline Laurane & $0.92 \pm 0.28^{b}$ & $0.006 \pm 0.01^{a}$ & $* * *$ & nd & nd & \\
\hline Zahaf & $0.006 \pm 0.01^{\mathrm{a}}$ & nd & $* * *$ & nd & nd & \\
\hline \multirow[t]{3}{*}{ Significance } & $* * *$ & * & & & & \\
\hline & \multicolumn{3}{|c|}{ Protocatechuic acid } & \multicolumn{3}{|c|}{ Catechin } \\
\hline & UAE & CSE & Significance & UAE & CSE & Significance \\
\hline Pizzuta & $0.22 \pm 0.01^{\mathrm{b}}$ & nd & $* * *$ & $2.40 \pm 0.08^{\mathrm{d}}$ & $0.06 \pm 0.04 \mathrm{ab}$ & $* * *$ \\
\hline Fascionello & $0.07 \pm 0.000^{\mathrm{a}}$ & nd & $* * *$ & $0.51 \pm 0.05^{b}$ & $0.003 \pm 0.001^{a}$ & $* * *$ \\
\hline Romana & $0.06 \pm 0.03^{\mathrm{a}}$ & nd & $* * *$ & $0.47 \pm 0.09^{b}$ & $0.01 \pm 0.0001^{\mathrm{b}}$ & $* * *$ \\
\hline Achaak & $0.04 \pm 0.01^{\mathrm{a}}$ & nd & $* * *$ & $1.51 \pm 0.03^{c}$ & $0.01 \pm 0.0001^{b}$ & $* * *$ \\
\hline Fakhfekh & $0.18 \pm 0.01^{b}$ & nd & $* * *$ & $6.91 \pm 0.16^{\mathrm{e}}$ & $0.02 \pm 0.0001^{b}$ & $* * *$ \\
\hline Laurane & $0.19 \pm 0.01^{b}$ & nd & $* * *$ & $0.53 \pm 0.20^{b}$ & $0.01 \pm 0.0001^{b}$ & $* * *$ \\
\hline Zahaf & $0.11 \pm 0.08^{a b}$ & nd & $* * *$ & $0.15 \pm 0.01^{\mathrm{a}}$ & $0.006 \pm 0.01^{\mathrm{a}}$ & $* * *$ \\
\hline \multirow[t]{3}{*}{ Significance } & $* * *$ & ns & & $* * *$ & $*$ & \\
\hline & & Caffeic Acid & & & & \\
\hline & UAE & CSE & Significance & & & \\
\hline Pizzuta & $0.08 \pm 0.01 \mathrm{ab}$ & nd & $* * *$ & & & \\
\hline Fascionello & nd & nd & & & & \\
\hline Romana & $0.02 \pm 0.01^{\mathrm{a}}$ & nd & $* * *$ & & & \\
\hline Achaak & $0.17 \pm 0.01^{b}$ & nd & $* * *$ & & & \\
\hline Fakhfekh & $0.17 \pm 0.05^{b}$ & nd & $* * *$ & & & \\
\hline Laurane & nd & nd & & & & \\
\hline Zahaf & nd & nd & & & & \\
\hline Significance & $* * *$ & & & & & \\
\hline
\end{tabular}

The total amount of polyphenols quantified by HPLC increased from 0.27 to $10.61 \mathrm{mg} / \mathrm{g}_{\mathrm{dw}}$ as following: Zahaf $<$ Romana $<$ Laurane $<$ Fascionello $<$ Achaak $<$ Pizzuta $<$ Fakhfekh, which confirmed 
that the differences observed in TPC could be related to the origin of almond. The highest concentrations of phenolic compounds in almond hull extracts were found in Fakhfekh $\left(11.61 \mathrm{mg} / \mathrm{g}_{\mathrm{dw}}\right)$ and Pizzuta $\left(7.54 \mathrm{mg} / \mathrm{g}_{\mathrm{dw}}\right)$ varieties with UAE. In particular, the Pizzuta variety was that with the highest levels of the identified polyphenols, except for catechin and caffeic acid, that were found in higher amounts in the Fakhfekh variety. On the other hand, the Zahaf variety yielded a low polyphenol content, characterized by the presence of only chlorogenic acid, catechin, and protocatechuic acid. The total amounts of the identified polyphenols for each variety were correlated with the TPC, TCT, and TFC values, with correlation values of $r=0.7406, r=0.8210$ and $r=0.7974$, respectively, and therefore, with the radical scavenging activity $(r=0.6424)$.

Generally, chlorogenic acid was the most abundant phenolic acid in the almond hull extracts. its content can be correlated $(r=0.688)$ with the antioxidant capacity displayed by the different varieties. Higher correlations were found for TPC, TCT, and TFC, with values of $r=0.787, r=0.854$, and $r=0.826$, respectively. Similar results were reported by Takeoka and Dao [39] for almond hull extracts obtained with methanol, wherein the authors identified three hydroxycinnamic acids with reversed phase HPLC-DAD: chlorogenic, cryptochlorogenic, and neochlorogenic acids. Wijeratne et al. [40] also identified flavonols and flavonol glycosides by HPLC as the major flavonoids in the almond green cover shell extracts.

In addition, Sang et al. [41] isolated protocatechuic acid, catechin, urosolic acid, and prenylated benzoic acid derivatives from almond hull extracts. Protocatechuic acid has been described in the literature as one of the major benzoic acid derivatives, with a high antioxidant capacity, and catechin is the most widely-distributed flavonoid in edible plants, with a high antioxidant activity and an inhibitory effect on numerous enzymes [2]. In this study, catechin was the second main compound and the most abundant for the Fakhfekh variety; therefore, it might be also considered as the main compound that contributes to the high antioxidant capacity observed in all of the studied extracts $(r=0.5157)$.

Rubilar et al. [42] reported the occurrence of benzoic and cinnamic acid derivatives, with a small presence of flavan-3-ols, epicatechin, and glycosilated flavonols by HPLC in almond hull extracts.

Wijeratne et al. [40] identified eight phenolic compounds, i.e., protocatechuic acid, quercetin 3-O-rhamnoside, kaempferol-3-O-glucoside, morin, kaempferol 3-O-rutinoside, isorhamnetin 3-O-glucoside, quercetin, and isorhamnetin, from the extracts of whole almond seed, the brown skin, and the hulls.

\section{Conclusions}

To our knowledge, this is the first study describing the polyphenols of almond hulls recovered from different varieties by applying UAE. Using the CCD and the RSM approach, the optimal UAE conditions were determined to enable the extraction of a high quantity of polyphenols from almond hulls, and to obtain the maximum antioxidant activity. We found that a solid:solvent ratio of $2 \mathrm{~g} / 100 \mathrm{~mL}$, an extraction time of $13 \mathrm{~min}$, and an ethanol concentration of $51.2 \%$ comprised the optimal UAE conditions. The results highlighted the potential of UAE technology to improve (up to 10 times) the recovery of bioactive compounds from almond hulls as a green extraction alternative to conventional extraction methods with feasible application on an industrial scale. Under these operating conditions, extracts from the hulls of the Fakhfekh and Pizzuta varieties showed the highest contents of polyphenolic compounds, condensed tannins, and flavonoids, and consequently, were also those with highest antioxidant capacity. Chlorogenic acid and catechin were identified and determined in higher amounts for Pizzuta and Fakhfekh hulls, respectively. Furthermore, these compounds were highly correlated with the antioxidant capacity displayed by the extracts yielded from these varieties. Our study highlighted the fact that the content of bioactive components in almond hulls is highly correlated with the variety, as reported in the literature for other vegetable products and byproducts. Finally, although the polyphenolic content in this almond byproduct was lower than in some other byproducts, our results confirmed that the almond hull can serve as a source of multiple bioactive 
compounds, which could be used not only for innovative and functional foods, but also as ingredients for pharmaceutical compounds.

Author Contributions: Conceptualization, M.K., L.B.P. and G.Z.; methodology, L.B.P. and G.Z.; software, G.Z.; formal analysis, M.K., S.B.D.V., F.G. and L.B.P.; writing-original draft preparation, M.K., H.B.H.K., N.B., L.B.P. and G.Z.; writing - review and editing, L.B.P. and G.Z.; funding acquisition, N.B. and G.Z.

Funding: This study was financially supported by the Ministry of Higher Education and Scientific Research and Tunisia Carthage University, under DP-2017-BALT "Academic and Educational Mission of Tunisia", as well as by the University of Torino, Research Direction and Doctorates Section, under mobility support from the Cotutelle Agreement Grant (No. D.D.n.2622).

Conflicts of Interest: The authors declare no conflict of interest.

\section{Abbreviations}

UAE: Ultrasound-assisted Extraction; CSE, Conventional Solvent Extraction; CCD, Central Composite Design; TPC, Total Phenolic Compounds; TCT, Total Condensed Tannins; TFC, Total Flavonoid Content; RSA, Radical Scavenging Activity; GAE, Gallic Acid Equivalent; TE, Trolox Equivalent; CE, Catechin Equivalent.

\section{References}

1. Food and Agriculture Organization of the United Nations. Available online: http://www.fao.org/faostat/en/ \#data/QC (accessed on 14 September 2019).

2. Prgomet, I.; Gonçalves, B.; Domínguez-Perles, R.; Pascual-Seva, N.; Barros, A. Valorization challenges to almond residues: Phytochemical composition and functional application. Molecules 2017, 22, 1774. [CrossRef]

3. Amarowicz, R.; Troszyńska, A.; Shahidi, F. Antioxidant activity of almond seed extract and its fractions. J. Food Lipids. 2005, 12, 344-358. [CrossRef]

4. Esfahlan, A.J.; Jamei, R.; Esfahlan, R.J. The importance of almond (Prunus amygdalus L.) and its by-products. Food Chem. 2010, 120, 349-360. [CrossRef]

5. Takeoka, G.; Dao, L.; Teranishi, R.; Wong, R.; Flessa, S.; Harden, L.; Edwards, R. Identification of three triterpenoids in almond hulls. J. Agric. Food Chem. 2000, 48, 3437-3439. [CrossRef] [PubMed]

6. Safarian, S.; Azarmi, Y.; Jahanban-Esfahlan, A.; Jahanban-Esfahlan, H. The beneficial effects of almond (Prunus amygdalus Batsch) hull on serum lipid profile and antioxidant capacity in male rats. Turk. J. Med. Sci. 2016, 46, 1223-1232. [CrossRef] [PubMed]

7. Bolling, B.; Dolnikowski, W.; Gregoryn, B.; Jeffrey, B.; Chen, C.-Y. Polyphenol content and antioxidant activity of California almonds depend on cultivar and harvest year. Food Chem. 2010, 122, 819-825. [CrossRef]

8. Taha, F.S.; Mohamed, G.F.; Mohamed, S.H.; Mohamed, S.S.; Kamil, M.M. Optimization of the extraction of total phenolic compounds from sunflower meal and evaluation of the bioactivities of chosen extracts. Am. J. Food Technol. 2011, 6, 1002-1020. [CrossRef]

9. Zardo, I.; De Espíndola Sobczyk, A.; Marczak, L.D.F.; Sarkis, J. Optimization of ultrasound assisted extraction of phenolic compounds from sunflower seed cake using Response Surface Methodology. Waste Biomass Valor. 2017, 10, 33-44. [CrossRef]

10. Fan, T.; Hu, J.; Fu, L.; Zhang, L.J. Optimization of enzymolysis-ultrasonic assisted extraction of polysaccharides from Momordica charabtia L. by response surface methodology. Carbohydr. Polym. 2015, 115, 701-706. [CrossRef]

11. Pongmalai, P.; Devahastin, S.; Chiewchan, N.; Soponronnarit, S. Enhancement of microwave-assisted extraction of bioactive compounds from cabbage outer leaves via the application of ultrasonic pre-treatment. Sep. Purif. Technol. 2015, 144, 37-45. [CrossRef]

12. Şahin, S.; Aybastıer, Ö.; Işık, E. Optimisation of ultrasonic-assisted extraction of antioxidant compounds from Artemisia absinthium using response surface methodology. Food Chem. 2013, 141, 1361-1368. [CrossRef] [PubMed]

13. Vilkhu, K.; Raymond, M.; Lloyd, S.; Darren, B. Applications and opportunities for ultrasound assisted extraction in the food industry-A review. Innov. Food Sci. Emerg. 2008, 9, 161-169. [CrossRef]

14. Pan, Y.; Hao, Y.; Chu, T.; Li, C.; Zhang, Z.; Zhou, Y. Ultrasonic-assisted extraction, chemical characterization of polysaccharides from Yunzhi mushroom and its effect on osteoblast cells. Carbohydr. Polym. 2010, 80, 922-926. [CrossRef] 
15. Tabaraki, R.; Ashraf, N. Optimization of ultrasonic-assisted extraction of natural antioxidants from rice bran using response surface methodology. Ultrason. Sonochem. 2011, 18, 1279-1286. [CrossRef]

16. Guglielmetti, A.; D’Ignoti, V.; Ghirardello, D.; Belviso, S.; Zeppa, G. Optimisation of ultrasound and microwave-assisted extraction of caffeoylquinic acids and caffeine from coffee silver skin using response surface methodology. Ital. J. Food Sci. 2017, 29, 409-424.

17. Jablonský, M.A.; Škulcová, A.; Malvis, A.; Šima, J. Extraction of value-added components from food industry based and agro-forest biowastes by deep eutectic solvents. J. Biotechnol. 2018, 282, 46-66. [CrossRef]

18. Azadeh, M. Acetone extract of almond hulls provides protection against oxidative damage and membrane protein degradation. J. Acupunct. Meridian Stud. 2016, 9, 134-142.

19. Singleton, V.L.; Rossi, J.A., Jr. Colorimetry of total phenolics with phosphomolybdic-phosphotungstic acid reagents. Am. J. Enol. Viticult. 1965, 16, 144-158.

20. Von Gadow, A.V.; Joubert, E.; Hansmann, C.F. Comparison of the antioxidant activity of rooibos tea (Aspalathus linearis) with green, oolong and black tea. Food Chem. 1997, 60, 73-77. [CrossRef]

21. Lin, J.T.; Liu, S.C.; Hu, C.C.; Shyu, Y.S.; Hsu, C.Y.; Yang, D.J. Effects of roasting temperature and duration on fatty acid composition, phenolic composition, Maillard reaction degree and antioxidant attribute of almond (Prunus dulcis) kernel. Food Chem. 2016, 190, 520. [CrossRef]

22. Barbosa-Pereira, L.; Guglielmetti, A.; Zeppa, G. Pulsed electric field assisted extraction of bioactive compounds from cocoa bean shell and coffee silverskin. Food Bioprocess Technol. 2018, 11, 818-835. [CrossRef]

23. Pan, X.; Niu, G.; Liu, H. Microwave-assisted extraction of tea polyphenols and tea caffeine from green tea leaves. Chem. Eng. Process. 2003, 42, 129-133. [CrossRef]

24. Spigno, G.; Tramelli, L.; De Faveri, D.M. Effects of extraction time, temperature and solvent on concentration and antioxidant activity of grape marc phenolics. J. Food Eng. 2007, 81, 200-208. [CrossRef]

25. Liu, Y.; Shoulian, W.; Liao, M. Optimization of ultrasonic extraction of phenolic compounds from Euryale ferox seed shells using response surface methodology. Ind. Crops. Prod. 2013, 49, 837-843. [CrossRef]

26. He, Q.; Du, B.; Xu, B. Extraction optimization of phenolics and antioxidants from black goji berry by accelerated solvent extractor using response surface methodology. Appl. Sci. 2018, 8, 1905. [CrossRef]

27. Wang, J.; Sun, B.; Cao, Y.; Tian, Y.; Li, X. Optimisation of ultrasound-assisted extraction of phenolic compounds from wheat bran. Food Chem. 2008, 106, 804-810. [CrossRef]

28. Cacace, J.; Mazza, G. Optimization of extraction of anthocyanin is from black currants with aqueous ethanol. J. Food Sci. 2003, 68, 240-248. [CrossRef]

29. Jiang, Z.; Shi, R.; Chen, H.; Wang, Y. Ultrasonic microwawe-assisted extraction coupled with macroporous resin chromatography for the purification of antioxidant phenolics from waste jackfruit (Artocarpus heterophyllus Lam.) peels. J. Food Sci. Technol. 2019, 56, 3877-3886. [CrossRef]

30. Yang, L.; Jiang, J.G.; Li, W.F.; Chen, J.; Wang, D.Y.; Zhu, L. Optimum extraction process of polyphenols from the bark of Phyllanthus emblica L. based on the response surface methodology. J. Sep. Sci. 2009, 32, 1437-1444. [CrossRef]

31. Dahmoune, F.; Boulekbache, L.; Moussi, K.; Aoun, O.; Spigno, G.; Madani, K. Vaporization of Citrus lemon residues for the recovery of antioxidants: Evaluation and optimization of microwave and ultrasound application to solvent extraction. Ind. Crops. Prod. 2013, 50, 77-87. [CrossRef]

32. Dahmoune, F.; Nayak, B.; Moussi, K.; Remini, H.; Madani, K. Optimization of microwave-assisted extraction of phenolics from Mirtus communis L. leaves. Food Chem. 2015, 166, 585-595. [CrossRef] [PubMed]

33. Carini, M.; Aldini, G.; Bombardelli, E.; Morazzoni, P.; Maffei Facino, R. UVB-induced haemolysis of rat erythrocytes: Protective effect of procyanidins from grape seeds. Life Sci. 2000, 67, 1799-1814. [CrossRef]

34. Juntachote, T.; Berghofer, E.; Bauer, F.; Siebenhandl, S. The application of response surface methodology to the production of phenolic extracts of lemon grass, galangal, holy basil and rosemary. J. Food Sci. Technol. 2006, 41, 121-133. [CrossRef]

35. Hifza, A.; Tariq, M.I.; Sultana, N.; Nosheen, S.; Habib, F.; Shafiq, M. Extraction and bio analysis of ultrasonic assisted Pakistani cultivar Prunus Dulcis seed: An optimization study. Pak. J. Sci. 2018, 70, 1.

36. Ryu, D.; Koh, E. Application of response surface methodology to acidified water extraction of black soybeans for improving anthocyanin content, total phenols content and antioxidant activity. Food Chem. 2018, 261, 260-266. [CrossRef]

37. Pinelo, M.; Rubilar, M.; Sineiro, J.; Nunez, M.J. Extraction of antioxidant phenolics from almond hulls (Prunus amygdalus) and pine sawdust (Pinus pinaster). Food Chem. 2004, 85, 267-273. [CrossRef] 
38. Subhashinee, S.K.; Siriwardhana, W.; Shahidi, F. Antiradical activity of extracts of almond and its by-products. J. Am. Oil. Chem. Soc. 2002, 79, 903-908.

39. Takeoka, G.R.; Dao, L.T. Antioxidant constituents of almond [Prunus dulcis (Mill.) DA Webb] hulls. J. Agric. Food Chem. 2003, 51, 496-5015. [CrossRef]

40. Wijeratne, S.S.L.; Abou-Zaid, M.M.; Shahidi, F. Antioxidant polyphenols in almond and its coproducts. J. Agric. Food Chem. 2006, 54, 312-318. [CrossRef]

41. Sang, S.; Lapsley, K.; Rosen, R.T.; Ho, C.T. New prenylated benzoic acid and other constituents from almond hulls (Prunus amygdalus Batsch). J. Agric. Food Chem. 2002, 50, 607-609. [CrossRef]

42. Rubilar, M.; Pinelo, M.; Shene, C.; Sineiro, J.; Nuñez, M.J. Separation and HPLC-MS identification of phenolic antioxidants from agricultural residues: Almond hulls and grape pomace. J. Agric. Food Chem. 2007, 55, 10101-10109. [CrossRef] [PubMed]

(C) 2019 by the authors. Licensee MDPI, Basel, Switzerland. This article is an open access article distributed under the terms and conditions of the Creative Commons Attribution (CC BY) license (http://creativecommons.org/licenses/by/4.0/). 